Jap. J. Physiol., 24, 119-133, 1974

\title{
EFFECTS OF TETRAETHYLAMMONIUM ON THE ELECTRICAL ACTIVITY OF PREGNANT MOUSE MYOMETRIUM AND THE INTERACTION WITH MANGANESE AND CADMIUM
}

\author{
Takuro OsA \\ Department of Physiology, Faculty of Dentistry, Kyushu University, Fukuoka 812, Japan
}

\begin{abstract}
Summary The effect of tetraethylammonium (TEA) on the electrical activity of mouse myometrium was investigated in combination with the use of Mn and Cd.

1. With low concentration of TEA ( $3 \mathrm{~mm})$, the overshoot of the spike potential increased by about $10 \mathrm{mV}$. With high concentration (10$30 \mathrm{~mm}$ ), the overshoot was increased more and the repolarization was prolonged. The rate of rise of the spike potential increased by $3 \mathrm{~mm}$ TEA, but higher concentrations did not cause further increase.

2. Membrane potential was not changed by TEA nor was the electrotonic potential in response to the hyperpolarizing current affected. In the Mn-Locke solution, where Ca was substituted with $2.2 \mathrm{~mm} \mathrm{Mn}$ and spike generation was abolished, the electrotonic response to the depolarizing current became larger when TEA was applied.

3. The spike potential, which had been once abolished in the Mn-added Locke solution, reappeared by applying TEA. TEA did not restore the spike generation in Cd-treated tissue.

4. Spike potential in Locke solution with $\mathrm{Mn}$ - and TEA-added was gradually suppressed by repetitive electric stimuli with $1 \mathrm{~Hz}$. It was restored by interposing longer intervals or by raising external $\mathrm{Ca}$ concentration.
\end{abstract}

The ineffectiveness of tetrodotoxin in suppressing spike potential and the effectiveness of $\mathrm{Mn}$ have been taken as pharmacological indications which suggest Ca spikes in many smooth muscles (see for review, BüLBRING et al., 1970). On the other hand, tetraethylammonium (TEA), which is known to cause $\mathrm{K}$ inactivation in various membranes, has been shown to increase the amplitude of the spike potential in some smooth muscles (Ito et al., 1970; OsA and KurIYAMA, 1971; BecK and Osa, 1971; Horn et al., 1972; Tomita and Watanabe, 1973). The

Received for publication November 19, 1973

長 环朗 
potentiating action of TEA on the spike generation was similarly observed in other excitable tissue in which the spike potential depends wholly or partially on the Ca influx (FAtT and Ginsborg, 1958; Koketsu and NaKatake, 1973; Iwasaki et al., 1973).

It was found in the present experiment that TEA caused an increase in the overshoot of the spike potential of mouse myometrium. More interestingly, the spike potential once abolished by the treatment with $1.2 \mathrm{~mm} \mathrm{Mn}$ reappeared when 3-10 mM TEA was applied. This seemed puzzling because one may not expect the effect provided that the potentiating effect of TEA on the spike potential depends on the decrease in $\mathrm{K}$ permeability alone. In the present experiment, the effect of TEA was investigated in combination with the use of various concentrations of $\mathrm{Ca}, \mathrm{Mn}$, and $\mathrm{Cd}$.

\section{METHODS}

Experiments were performed on the late pregnancy (15-20 days) mouse myometrium. Methods of obtaining the muscle strip, the arrangements of electrical and mechanical activities were the same as those described in an earlier paper (OsA, 1974). A modified Locke solution equilibrated with $97 \% \mathrm{O}_{2} 3 \% \mathrm{CO}_{2}$ was used. Experiments were carried out at $34^{\circ} \mathrm{C}$. The drug used was TEA-Cl (ParkDavis Pharm. Co.) and the concentration was given in mM.

\section{RESULTS}

\section{Effects of TEA on electrical and mechanical activities}

Figure 1 shows the effects of $10 \mathrm{~mm}$ TEA on the electrical and mechanical activities of the mouse myometrium. Record A shows control, and B the onset of the TEA action. The amplitude of the spike potential immediately started to increase when TEA was administrated until the amplitude of the overshoot became consistent in about $5 \mathrm{~min}$. Records $\mathrm{C}$ and $\mathrm{D}$ show the activities after 2 and $5 \mathrm{~min}$ exposure to $10 \mathrm{~mm}$ TEA, respectively. In the steady state (D), the occurrence of bursts became frequent and the duration shorter. The amplitude of slow potential was nearly the same as control, but the frequency of spike potential became less frequent. Since the magnitude and time sequence of the spontaneous mechanical activity depended largely on the frequency of spike potentials in the burst, the primary effect of TEA on the mechanical response was difficult to find. The membrane potential remained at the same level throughout before and after the treatment with TEA. Records shown in a to $d$ are those taken on fast sweep, each corresponding to the capital alphabets in upper records. These indicate, in addition to above findings, that the repolarizing phase of the action potential was prolonged by the treatment with TEA. The effects of TEA concentration $(3-30 \mathrm{~mm})$ on the evoked spike potential was investigated in the experi- 


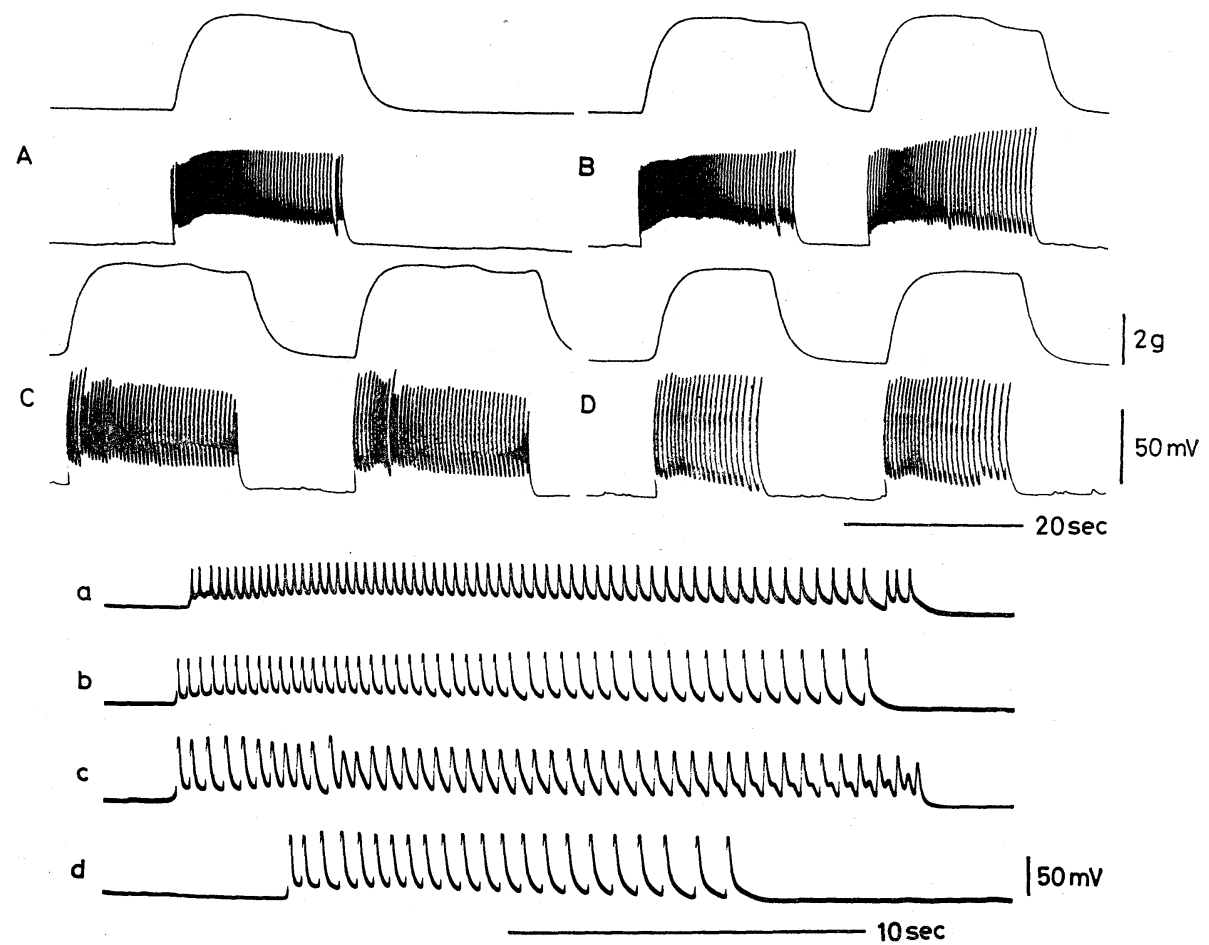

Fig. 1. (A)-(D); effects of $10 \mathrm{~mm}$ TEA on the mouse myometrium, mechanical (upper trace) and intracellular electrical (lower trace) activities. (A) control, (B) onset of TEA action, (C) and (D) taken 2 and $5 \mathrm{~min}$ after the TEA application respectively. (a)-(d), intracellular records of the corresponding capital alphabets of upper records on fast sweep.

ment shown in Fig. 2. The arrangements for the external stimulation and recording the intracellular response were such that described by ABE and TOMITA (1968). The records were from the same cell and the responses were taken after about $5 \mathrm{~min}$ equilibration in the test solution. With $3 \mathrm{~mm}$ TEA (b), the overshoot of the evoked spike potential increased by $10 \mathrm{mV}$, and the maximal rate of rise from $9.5 \mathrm{v} / \mathrm{sec}$ of the control to $13 \mathrm{v} / \mathrm{sec}$. With higher concentration $(\mathrm{c}, \mathrm{d})$, the overshoots were further increased and the duration of the spike potential was prolonged. This was mainly due to the slow repolarization. No change in the membrane potential nor the further increase in the maximal rate of rise of spike potential occurred with 10-30 mM TEA.

In order to find out the possible change in the membrane property, the effect of $10 \mathrm{~mm}$ TEA on the electrotonic potential produced by the external current application was investigated in the experiment shown in Fig. 3. The electrotonic potentials were produced by hyperpolarizing current pulses with $500 \mathrm{msec}$ duration and 3 different intensities. Although the time course of the electrotonic 

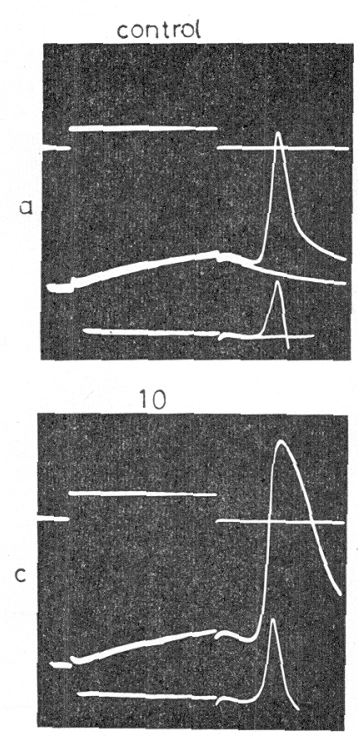

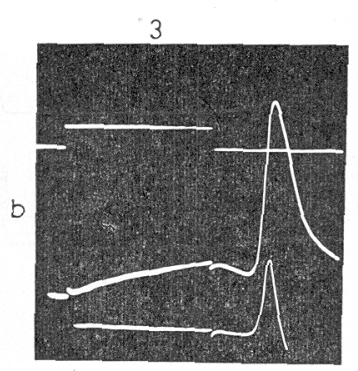

$30(\mathrm{mM}$ TEA $)$

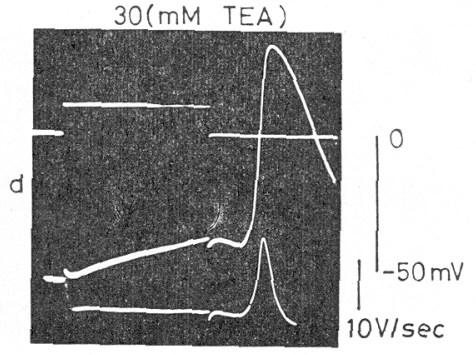

$300 \mathrm{msec}$

Fig. 2. Effects of various concentrations of TEA (3, 10, $30 \mathrm{~mm}$ for b, c, d, respectively) on the evoked spike potential of mouse myometrium. Records were taken at about 5 min exposure to test solution. Top beam, relative intensity of stimuli; middle, intracellular spike potential; bottom, differentiated spike potential with $\mathrm{AC}$ circuit having $1 \mathrm{msec}$ time constant. Records from the same cell, the distance between the nearest stimulating electrode and microelectrode being $0.5 \mathrm{~mm}$. Unless otherwise described in the following captions, the distance between the stimulating and the recording electrodes was nearly the same.

potentials was complicated by the electrotonic spread of the spike potential (evoked by the depolarization at the other stimulating electrode), no significant change in the amplitude of the electrotonic potential was observed by the application of $10 \mathrm{~mm}$ TEA. The conclusion was the same with $30 \mathrm{~mm}$ TEA. In this particular cell, the spike was followed by negative afterpotential (a). The overshoot as well as the negative afterpotential increased with the application of TEA.

It was reported in earlier papers that the membrane potential and the amplitude of the spike potential of the pregnant mouse myometrium increases when the external $\mathrm{Ca}$ concentration is increased, while the overshoot remains nearly unchanged (OSA and TAGA, 1973; OSA, 1973a). With excess Ca concentration $(11 \mathrm{~mm})$ in Locke solution, the increase in the overshoot and the maximal rate of rise of spike potential by TEA were more potentiated (Fig. 4). In the presence of $3 \mathrm{~mm}$ TEA the average of overshoot potential in normal Locke solution was $13 \mathrm{mV}$ and it was $25 \mathrm{mV}$ in the solution containing $11 \mathrm{~mm} \mathrm{Ca}$.

One of the outstanding effect of TEA was manifested when the frequency response of mechanical activity was investigated. The arrangement of the elec- 

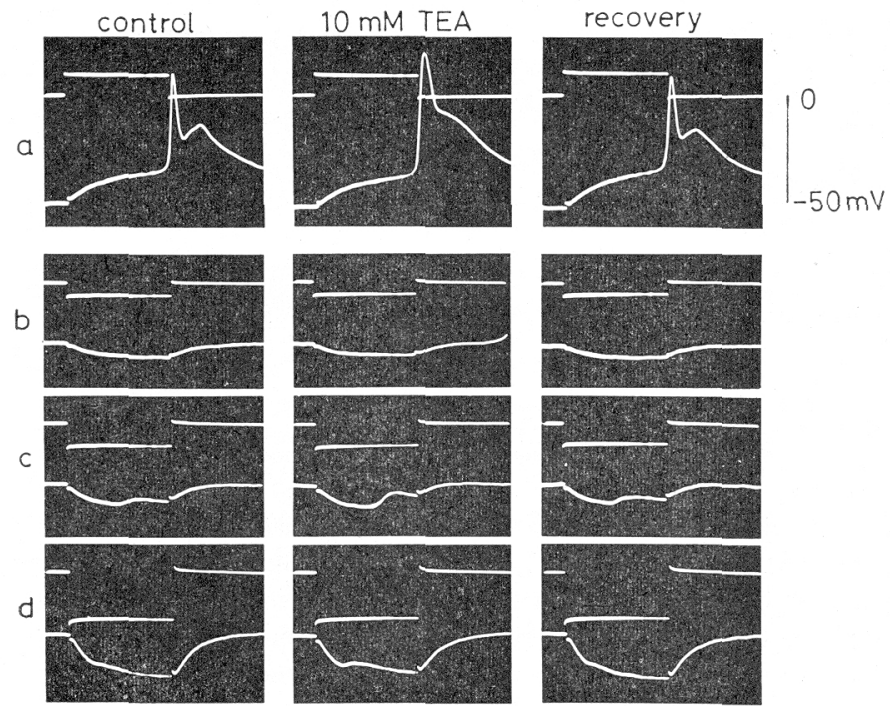

$500 \mathrm{msec}$

Fig. 3. Effects of $10 \mathrm{mM}$ TEA on the evoked spike potential (a) and electrotonic potentials (b, c, d). Responses to the hyperpolarizing stimuli were taken with three different current intensities. (a) control, (b) 4 min after treatment with TEA, (c) 10 min after the exposure to normal Locke solution. Records from the same cell.
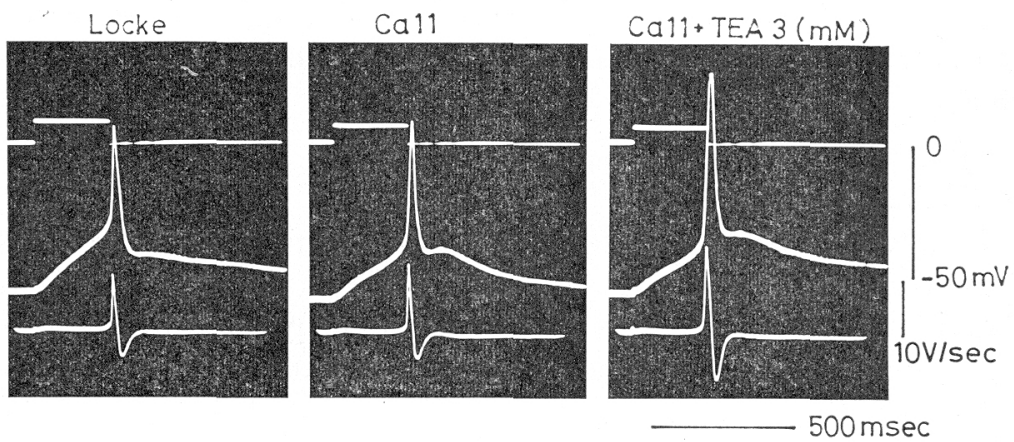

Fig. 4. Effects of excess $\mathrm{Ca}(11 \mathrm{~mm})$ and $3 \mathrm{~mm}$ TEA on the evoked spike potential.

tric stimulation of the muscle strip was the same as described in an accompanying paper (OsA, 1974). In normal Locke solution, the tetanic stimulation (200 msec duration, $1 \mathrm{~Hz}$ ) did not produce sustained contraction in the mouse myometrium. Usually the phasic contraction developed initially, then the tonic contraction ensued. In most cases, phasic contraction was superposed on the tonic contraction during the application of repetitive electrical pulses (Fig. 5a, left). When $10 \mathrm{~mm}$ TEA was administrated, the contraction became sustained in response to 


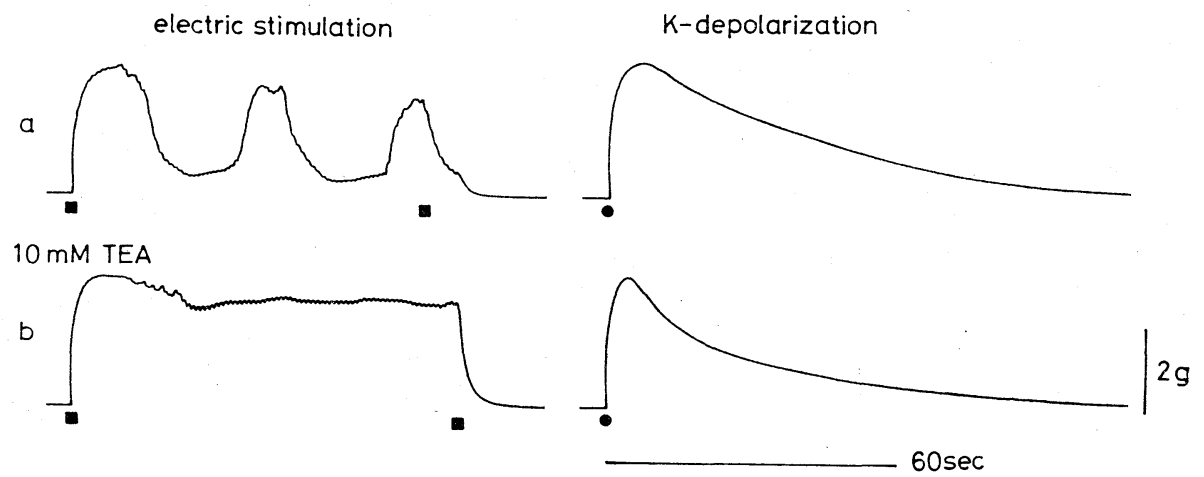

Fig. 5. Mechanical responses to electric stimulation (200 msec duration and $1 \mathrm{~Hz}$ frequency, left column) and to isotonic $\mathrm{K}$ solution (right column). Electric pulses were applied during the time interpolated between black squares, and isotonic $\mathrm{K}$ solution was applied at the time indicated by black circle. Responses in the absence (a) and the presence of $10 \mathrm{mM}$ TEA (b). Records in (b) were those taken after the previous exposure to a solution with TEA-added for $10 \mathrm{~min}$, and in response to $\mathrm{K}$ solution containing $10 \mathrm{mM}$ TEA.

the same train pulses (b, left). In the TEA-treated tissue, the peak response of the $\mathrm{K}$ contracture was unaltered but the decay of phasic contraction emerging to tonic contraction was accelerated (b, right). Because the effect of TEA on the $\mathrm{K}$ contracture is rather inhibitory, it may be suggested that the change in the mechanical response to the electric stimuli was chiefly due to that in the membrane excitability.

\section{Interaction between $\mathrm{Mn}$ and TEA}

It is widely appreciated that generation of Ca-spike can be antagonized by Mn perhaps owing to competition at the Ca site of the membrane (HAGIWARA and TAKAHASHI, 1967). Possibly another action of polyvalent cations might be directed against certain Ca-dependent mechanism in the spike generation as well as in the regulation of ionic permeability of the membrane (CHIARANBINI and STEFANI, 1973). In the experiment shown in Fig. 6, the effects of TEA (10 and $30 \mathrm{~mm}$ ) on the spike generation were investigated in the solutions containing 2 different Mn concentrations. The tissue was stimulated by depolarizing current pulses with 2 different intensities. The complete suppression of spike generation was achieved in this preparation when $1.2 \mathrm{~mm} \mathrm{Mn}$ was given. Records in $\mathrm{b}$ indicate that the spikes made abortive by $0.6 \mathrm{~mm} \mathrm{Mn}$ application were restored when TEA was applied. Duration of the action potential was prolonged at the same time. The application of TEA caused a reappearance of spike potentials once abolished by $1.2 \mathrm{~mm} \mathrm{Mn}(\mathrm{c})$. The prolongation of the repolarization phase was more pronounced when the Mn concentration was higher. 


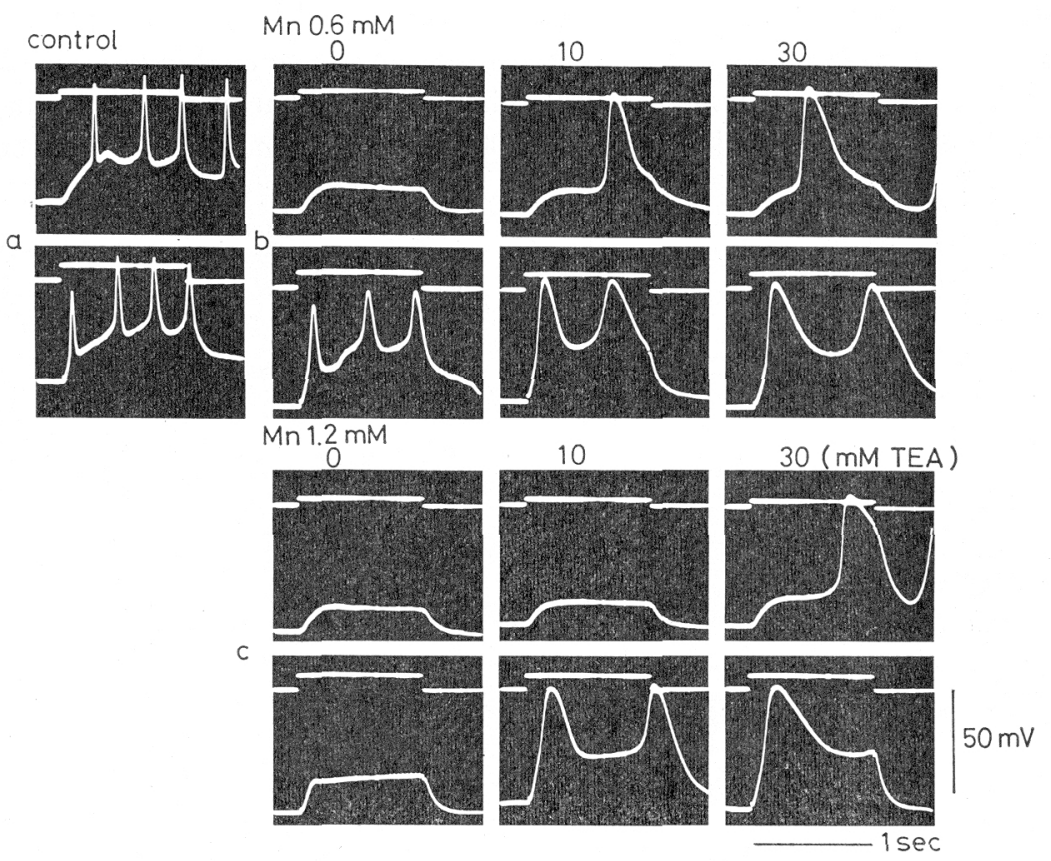

Fig. 6. Effect of 10 and $30 \mathrm{~mm}$ TEA in the presence of $0.6 \mathrm{~mm}$ (b), and $1.2 \mathrm{~mm} \mathrm{Mn} \mathrm{(c)} \mathrm{on} \mathrm{the}$ evoked spike potentials. TEA was applied after 20 min pretreatment with $\mathrm{Mn}$. Depolarizing stimuli with two different current intensities were applied. The upper beam shows the relative intensity of the stimuli alone, but not the zero level.

So far as is known, TEA affected the frequency response of the mechanical activity in normal media (Fig. 5), and restored the spike generation in the Mntreated mouse myometrium (Fig. 6). The interaction between Mn and TEA was investigated in the experiment shown in Fig. 7 by recording the mechanical activities produced by repetitive electrical stimulation (left column) and by applying an isotonic $\mathrm{K}$ solution (right column). Contraction in response to the electrical stimuli (200 msec duration, $1 \mathrm{~Hz}$ ) was much depressed when $1.2 \mathrm{~mm}$ Mn was applied ( $b$, left). It is evident that this was due to the abolition of the spike potential, because $K$ depolarization caused a contracture ( $b$, right), the amplitude of the tonic contracture being larger than the control response. It may be also suggested that the muscle membrane was depolarized enough by the electric current to cause the spike generation with this method, but the extent of depolarization was far smaller compared with that of applying isotonic $\mathrm{K}$. By adding $10 \mathrm{~mm}$ TEA, contraction was produced by the electrical stimulation but it was not maintained ( $\mathrm{c}$, left). In the simultaneous presence of $1.2 \mathrm{~mm} \mathrm{Mn}$ and $10 \mathrm{~mm}$ TEA, the onset of $\mathrm{K}$ contracture was slightly faster and tonic contraction was slowly decaying (c, right). In a similar ionic composition, the effect of tetanic 
stimulation on the membrane response was investigated in the experiment shown in Fig. 8. The experimental arrangements were the same as those of Fig. 2, thus the method of external stimulation was different from that of Fig. 7. The tissue was stimulated by electrical pulses with $200 \mathrm{msec}$ duration and at a frequency of
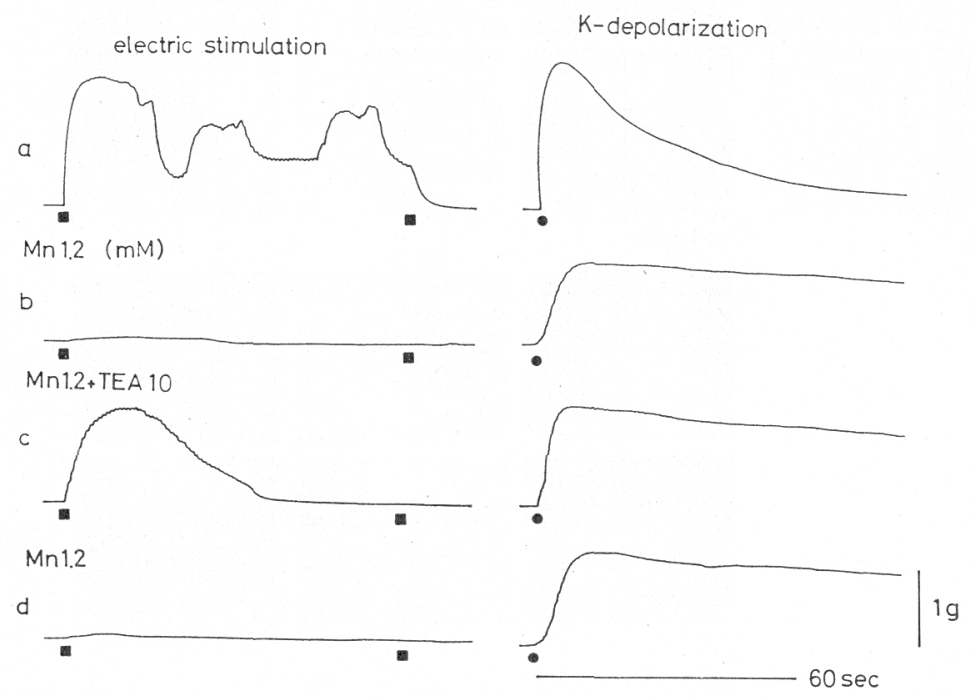

Fig. 7. Mechanical responses to electric stimulation (200 $\mathrm{msec}$ duration and $1 \mathrm{~Hz}$ frequency, left column) and to the isotonic $K$ solution (right column). (a) control, (b) in the presence of $1.2 \mathrm{~mm} \mathrm{Mn}$ for $40 \mathrm{~min}$, (c) after adding $10 \mathrm{~mm}$ TEA for $5 \mathrm{~min}$, (d) $5 \mathrm{~min}$ after withdrawal of TEA. Marks indicate the same as for Fig. 5.

a
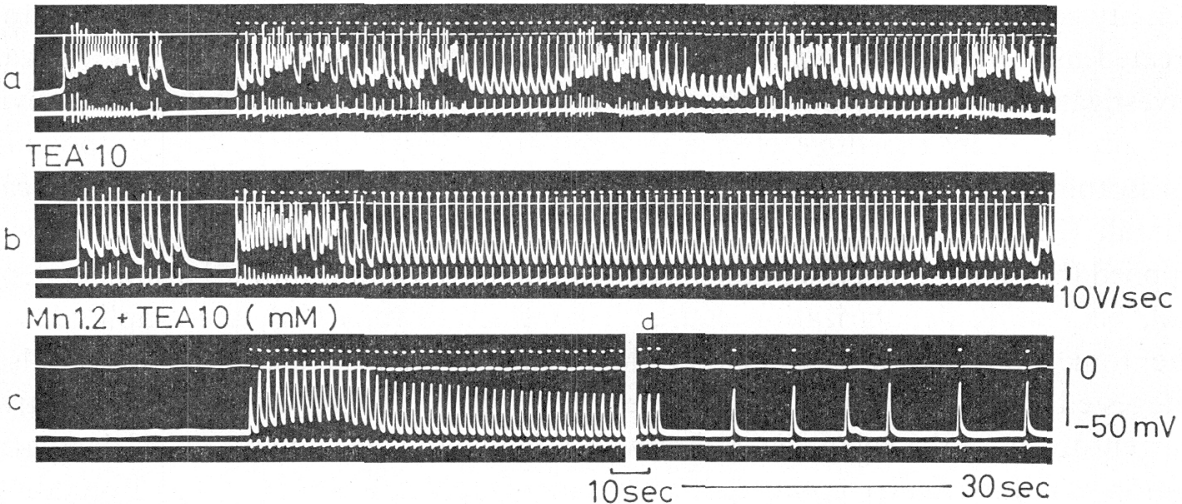

Fig. 8. Effect of $10 \mathrm{~mm}$ TEA (b) and the simultaneous application of $1.2 \mathrm{~mm} \mathrm{Mn}$ and $10 \mathrm{mM}$ TEA (c) on the spontaneous and the evoked membrane activities. Electric stimuli with $200 \mathrm{msec}$ duration and $1 \mathrm{~Hz}$ frequency were applied. (a) control, (d) successive record of (c), where the interval between stimuli was longer. 
$1 \mathrm{~Hz}$. In normal Locke solution, the response to each pulse varied (a). The variability of the response during the tetanic stimulation was characterized by the intermittent appearance of slow potential and the occasional inability to produce spike potential. The amplitude of the evoked spikes was inconsistent and spike potentials with larger amplitude was evoked when the slow potential was generated. The phenomenon might be possibly due to the temporal variation of the membrane excitability. Relative refractoriness was likely caused after the generation of slow potential. When the tissue was treated with $10 \mathrm{~mm}$ TEA, the response became almost consistent i.e. the burst discharge occurred initially however steady spike generation followed (b). Slow potential appears inhibited. These electrical events seem to parallel to the mechanical response presented in Fig. 5. When $1.2 \mathrm{~mm} \mathrm{Mn}$ was applied in addition, spikes were generated during earlier period of the tetanic stimulation, then the response became depressed (c). The evoked response was partially restored when the interval between the pulses was longer $(\mathrm{d})$.

The frequency response was further investigated in the experiment shown in Fig. 9. Records $\mathrm{a}$ and $\mathrm{b}$ are successive responses evoked by electrical pulses with the same intensity ( $200 \mathrm{msec}$ duration, $0.5 \mathrm{~Hz}$ ) and produced in the Locke solution

$\operatorname{Mn} 1.2, \mathrm{Ca} 2.2$

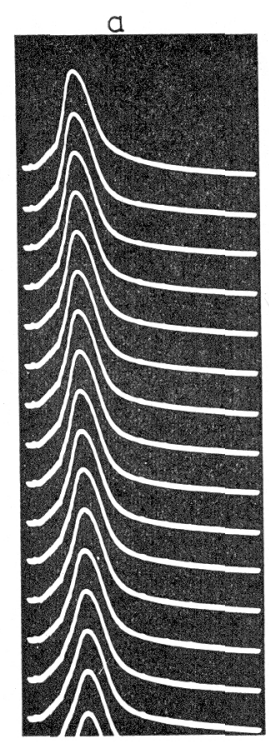

$\operatorname{Mn} 1.2, \operatorname{Ca} 11(\mathrm{mM})$

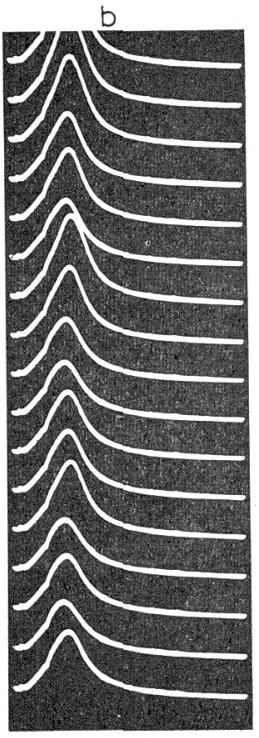

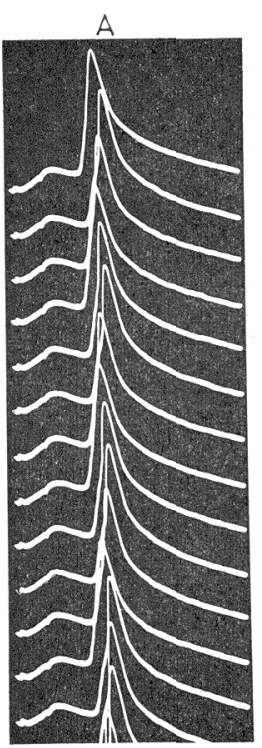

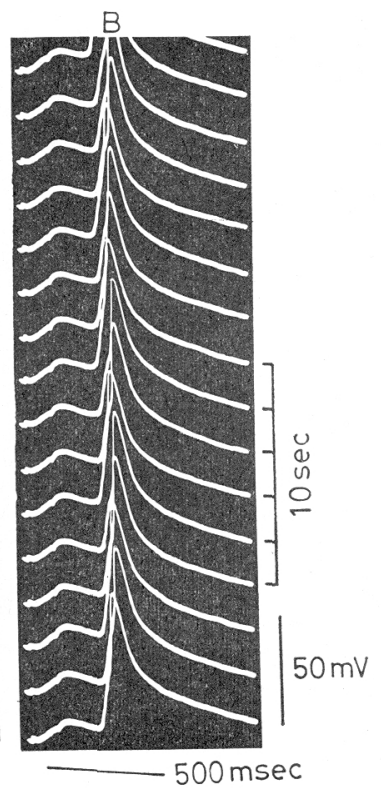

Fig. 9. Effects of repetitive electric stimuli with constant intensity ( $200 \mathrm{msec}$ duration and $0.5 \mathrm{~Hz}$ ) on the electrical responses in the Locke solutions containing $1.2 \mathrm{~mm} \mathrm{Mn}$ and $2.2 \mathrm{~mm} \mathrm{Ca} \mathrm{(a,} \mathrm{b),} \mathrm{and} \mathrm{1.2} \mathrm{mm} \mathrm{Mn}$ and $11 \mathrm{~mm} \mathrm{Ca} \mathrm{(A,} \mathrm{B).} \mathrm{Successive} \mathrm{records} \mathrm{from} \mathrm{top}$ of a (and $\mathrm{A}$ ) to the bottom of $\mathrm{b}$ (and B). $10 \mathrm{~mm}$ TEA was always present. 
containing 1.2 mM Mn and $10 \mathrm{~mm}$ TEA. The amplitude as well as the rate of rise of the evoked spikes were gradually depressed until a steady state was reached in about $30 \mathrm{sec}$ leaving a local response. The simultaneous record was displayed on the ink-writing oscillograph, and it was found that membrane potential remained unaltered during the tetanic stimulation. When interval of about $30 \mathrm{sec}$ was interposed, the membrane recovered to provide a prevailing control response, and a similar time sequence to the tetanic stimuli was reproduced. When the external Ca concentration was raised to $11 \mathrm{~mm}$ in the presence of $1.2 \mathrm{~mm} \mathrm{Mn}$ and $10 \mathrm{~mm}$ TEA (A, B), the membrane potential increased by $3 \mathrm{mV}$. The amplitude of the evoked spikes became larger and the response to tetanic stimulation became almost consistent. The prolongation of the action potential was also prevented in excess Ca solution ( $c f$. Fig. 6).

It seemed likely that the time course of contraction produced by the tetanic stimulation represented that of the spike generation (Figs. 5, 7, 8). The mechanical response to the electrical stimuli was investigated in the experiment shown in Fig. 10 where the external concentration of $\mathrm{Mn}$ and $\mathrm{Ca}$ was changed in the presence of $10 \mathrm{~mm}$ TEA throughout. In the solution containing $2.2 \mathrm{~mm} \mathrm{Ca}$ and 1.2 $\mathrm{mm} \mathrm{Mn} \mathrm{(a),} \mathrm{the} \mathrm{mechanical} \mathrm{response} \mathrm{was} \mathrm{phasic,} \mathrm{and} \mathrm{contraction} \mathrm{terminated}$ in spite of the continuous application of electric pulses. The mechanical response reverted to the sustained contraction when the external $\mathrm{Ca}$ concentration was raised to $11 \mathrm{~mm}$ (b). When the $\mathrm{Mn}$ concentration was then increased to $3.6 \mathrm{~mm}$, the mechanical response became again phasic (c), and this then reverted to sus-

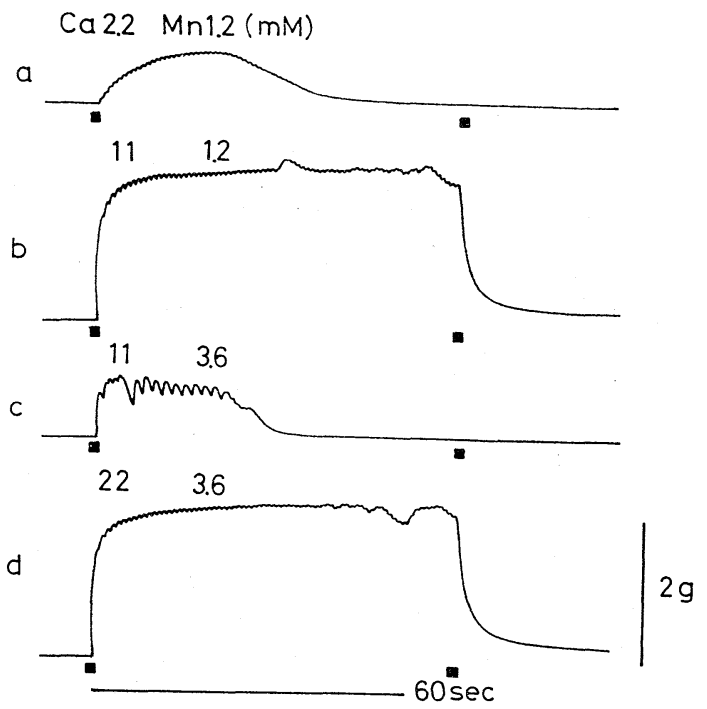

Fig. 10. Effects of repetitive stimuli $(200 \mathrm{msec}$ duration and $1 \mathrm{~Hz})$ on the mechanical responses in the Locke solutions containing various combination of external $\mathrm{Mn}$ and Ca concentrations. $10 \mathrm{~mm}$ TEA was always present. 
tained contraction when Ca concentration was further increased to $22 \mathrm{~mm}$ (d). In these mechanical records, the number of contraction wavelets equalled the stimulus frequency, therefore they were likely produced corresponding to each spike generation $(a, b, d)$. Hence, record c suggests that one excitation occurred as a result of two electric pulses in this ionic condition.

It was shown that treatment with $10 \mathrm{~mm}$ TEA did not produce a change in the membrane potential, nor was the membrane response to the hyperpolarizing current affected (Fig. 3). A difficulty existing in the determination of the change in the membrane property was spike generation when the depolarizing pulse was applied. An attempt was made to investigate the membrane response to the depolarizing current pulse in the solution, where external $\mathrm{Ca}$ was substituted with isosmolar Mn and the spike generation was suppressed (Fig. 11). Ca-free solution was prepared merely by omitting Ca. After about $30 \mathrm{~min}$ immersion in the Mn-Locke solution, when the membrane potential was $-53 \mathrm{mV}$, the experiment was performed. Membrane potential was shifted by applying a conditioning current to either the depolarizing or the hyperpolarizing direction, and the change in the membrane response to the test pulses with constant intensity was investigated. Records are those in the absence (A, B) or presence of $10 \mathrm{~mm}$ TEA
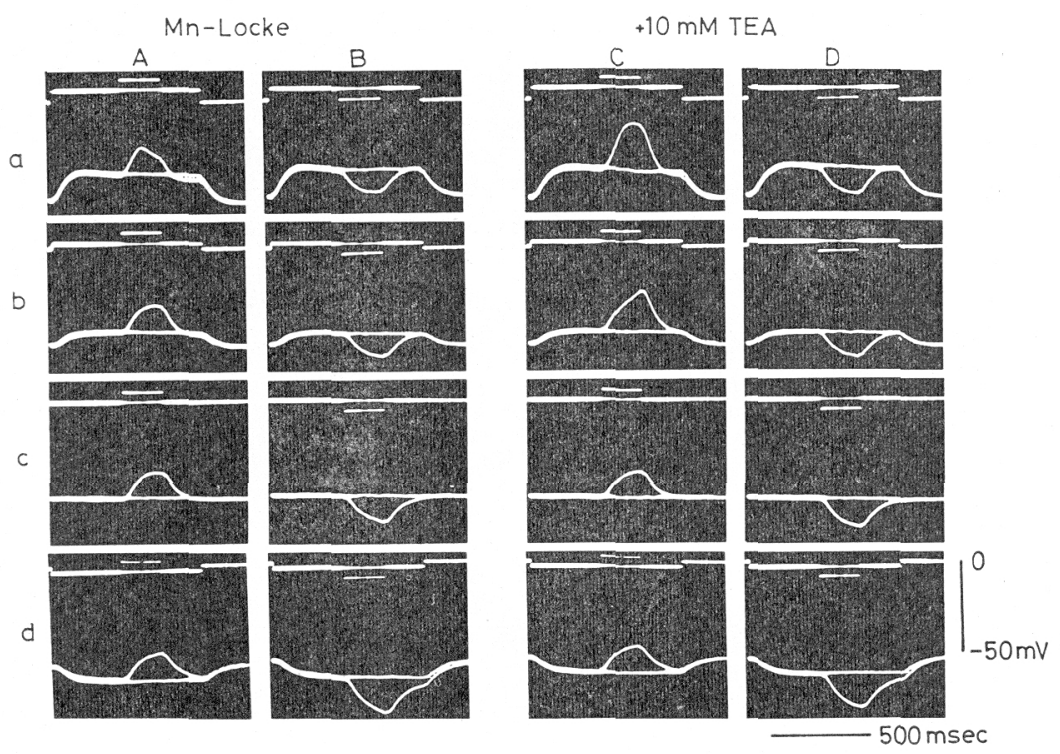

Fig. 11. Effect of $10 \mathrm{~mm}$ TEA on the electrotonic potential in the Mn-Locke solution, where $\mathrm{Ca}$ was omitted and $2.2 \mathrm{~mm} \mathrm{Mn}$ was added. After the tissue was exposed to the Mn-Locke for $30 \mathrm{~min}$, the records were taken. Membrane potential was shifted to depolarizing direction ( $\mathrm{a}, \mathrm{b})$, or hyperpolarizing direction (d) by conditioning long pulse, on which depolarizing $(A, C)$ or hyperpolarizing $(B, D)$ test pulse with constant intensity and duration was superposed. 
(C, D). The resting potential remained unaltered in both solutions. As shown in the series records in $\mathrm{A}$, the electrotonic potential to the depolarizing test pulse did not show remarkable difference in the range of -45 to $-65 \mathrm{mV}$ of membrane potential (b-d). When the membrane potential was decreased to less than $-40 \mathrm{mV}$ by conditioning depolarization (a), response to the test pulse became smaller, suggesting the rectifying property of the membrane. The response to the hyperpolarizing test pulse (B) was essentially the same at the membrane potential of -30 to $-55 \mathrm{mV}(\mathrm{a}-\mathrm{c})$. When membrane was hyperpolarized to $-65 \mathrm{mV}$, the response became larger (d).

A noticeable event in the membrane response could be observed in the solution with TEA added when the membrane was depolarized by conditioning current (C). The membrane response to the depolarizing test pulse became larger $(a, b)$. As to other records $(C, c-d ; D, a-d)$, the membrane response was the same as that with the control $(\mathrm{A}, \mathrm{B})$.

\section{Interaction between $C d$ and TEA}

Contrasting the effect of TEA on the Mn-treated tissue (Fig. 6), $10 \mathrm{~mm}$ TEA was incapable of producing spike potential in tissue treated with $0.5 \mathrm{~mm} \mathrm{Cd}$

Locke

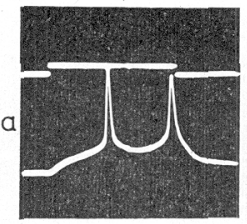

TEA 10

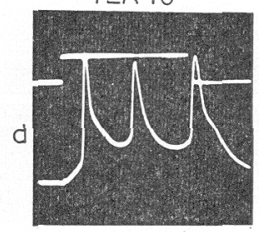

TEA

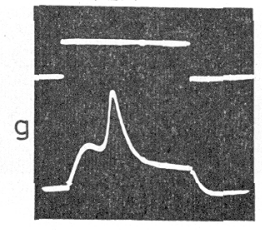

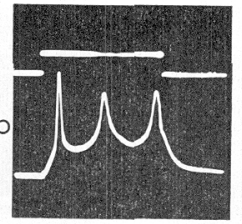

Cd $0.5(\mathrm{mM})$

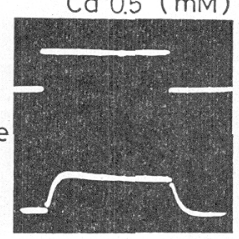

Locke

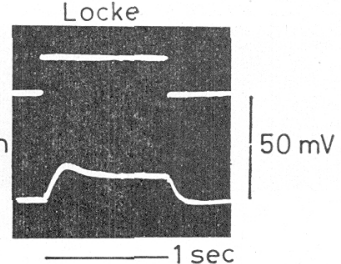

Fig. 12. Effects of $0.5 \mathrm{~mm} \mathrm{Cd}$ and $10 \mathrm{~mm}$ TEA on the evoked spike activity. (a)-(c), membrane response in normal Locke solution to depolarizing current with three different intensities; (d) effect of TEA, (e) effect of Cd, (f) response in the simultaneous presence of $\mathrm{Cd}$ and TEA, (g) response during the withdrawal of $\mathrm{Cd}$ after 10 min application, (h) response during $30 \mathrm{~min}$ exposure to normal Locke. 
(Fig. 12f). As described in an accompanying paper (OsA, 1974), the suppressing action of $\mathrm{Cd}$ on the spike generation of mouse myometrium was very potent and persisted for about 10-60 min in normal saline, the period varying according to the concentration and the duration of Cd-pretreatment. During this less reactive period, TEA caused a restoration of the spike potential, however, to a lesser extent (Fig. 12g). In accordance with the results described in the previous paper, the effect of $\mathrm{Cd}$ is distinguished from that of $\mathrm{Mn}$ again in the present results.

\section{DISCUSSION}

There is enough reason to suppose that the increase in the overshoot and the prolongation of the spike potential are due to the decrease in $\mathrm{K}$ permeability, which is shown in fact to occur with TEA in gastric muscle of guinea pig (ITO et al., 1970). The present experimental results indicate that the change in the spike generation is by no means correlated to that of the resting membrane property because the membrane potential of mouse myometrium remained unchanged by the treatment with TEA, the concentration ranging from $3 \mathrm{~mm}$ to $30 \mathrm{~mm}$, and the amplitude of electrotonic potentials produced by the hyperpolarizing current was unaltered. Based on the assumption that the effect of TEA was not essentially changed in the Mn-Locke solution, where external Ca was substituted with $2.2 \mathrm{~mm}$ $\mathrm{Mn}$, the results shown in Fig. 11 may afford information as to TEA action, where the change in the membrane property was revealed only when the membrane was depolarized above a certain potential level by a conditioning current and a depolarizing test pulse was applied. Because spike generation was very probably suppressed in this solution, the membrane response to the depolarizing test pulse can be ascribed to the change in rectifying property which was caused by TEA, although further investigation is necessary to choose the alternative ion species. Assuming that the $\mathrm{K}$ inactivation upon depolarization was responsible for the increase in the amplitude and the rate of rise of spike potential, it can be further supposed that at least two components in $\mathrm{K}$ permeability change are distinguishable, which may determine the amplitude as well as the time course of falling phase of action potential. From the effect of concentrations of TEA on the spike potential (Fig. 2), it might be that TEA suppressed the early component of $\mathrm{K}$ permeability increase upon depolarization, at first by low concentration hence causing the increase in the rate of rise of spike potential, whilst higher concentration was needed to suppress the late component to cause further increase in the amplitude and prolongation of spike potential. The blockade of the $\mathrm{K}$ pore (with a wide inner mouth) in squid giant axon has been assumed due to the similar hydrated size of TEA as that of K ion (ARMSTRONG, 1971).

A feature of the TEA action in mouse myometrium investigated in combination with the use of $\mathrm{Ca}$ and $\mathrm{Mn}$ is that not only the spike amplitude but also the frequency response to the electric stimuli were changed according to the ratio 
of $\mathrm{Ca}$ vs. Mn (Fig. 10). Therefore, the question arose whether or not every action of TEA on the spike generation can be ascribed to $\mathrm{K}$ inactivation. It has been shown that $\mathrm{Ca}$ relates the gate mechanism of spike generation so that raising the external $\mathrm{Ca}$ concentration removes the inactivation process without causing a change in the membrane potential of the squid axon or the Purkinje fibres (Weidmann, 1955; Frankenhaeuser and Hodgkin, 1957). When the action potentials are forced to be generated, a sizable amount of labeled Ca leaks out in the external media (Shanes and Bianchi, 1960; Konetsu and Miyamoto, 1961). This was taken as an indication that $\mathrm{Ca}$ is released from the membrane when the gate mechanism for the spike generation was activated. It might be, therefore, reasonable to presume that the secondary step for the generation of spike potential is limited by the gate mechanism, which is normally maintained by occupation of the site by $\mathrm{Ca}$ and might be inactivated by the occupation by Mn. When the gate mechanism was activated by the tetanic electric stimuli in the presence of TEA and predominant $\mathrm{Mn}$ ions, the rate of occupation by $\mathrm{Mn}$ might be accelerated, hence causing the progressive suppression of spike generation (Figs. 8 and 9). An equilibrium state of the resting membrane could be achieved in time, if the external stimulation is stopped. In this connection, it is worthy to mention that maculotoxin is known to cause the effects provided that the gate mechanisms is activated (DULHUNTY and GAGE, 1971). Together with the speculation described above, it can be supposed that the potentiating action of TEA on the spike potential is brought about by apparently different mechanisms: First, $\mathrm{K}$ inactivation upon depolarization; Secondly, the removal of inactivation in the spike generating process. In these mechanisms, modification of the interaction between the membrane and $\mathrm{Ca}$ might be involved. In the earlier discussion, effects of concentrations on spike potential was ascribed to the suppression of early and late components of $\mathrm{K}$ permeability change. Because TEA is likely penetrating the membrane owing to the comparable hydrated size of $\mathrm{K}$ ion and/or to the lipid solubility, an alternative postulation of the effects of concentration might be that the removal of inactivation by low concentration was due to the TEA action onto the outer surface of the membrane, and $\mathrm{K}$ inactivation to cause the prolongation of spike potential by higher concentration onto the inner surface of cell membrane.

TEA does not seem completely out of action in affecting the mechanical response of mouse myometrium, since decay of $\mathrm{K}$ contracture was accelerated in the presence of the agent (Fig. 5), the feature bearing a resemblance as with raising external K concentration (OsA, 1973b). Furthermore, spike potentials reappeared and contraction developed in a media with Mn added, when TEA was administrated (Figs. 7 and 8). Provided that intracellular $\mathrm{Ca}$ sequestering sites were masked by treatment with $\mathrm{Mn}$, the above results might be taken as an indication that $\mathrm{Ca}$ influx during the spike generation was responsible for the tension development. 
The author expresses his appreciation to Prof. H. Kuriyama for reading the manuscript and for giving valuable suggestions.

\section{REFERENCES}

AвE, Y. and Tomita, T. (1968) Cable properties of smooth muscle. J. Physiol., 196: 87-100. Armstrong, C. M. (1971) Interaction of tetraethylammonium ion derivatives with the potassium channels of giant axons. J. Gen. Physiol., 58: 413-437.

BeCK, C. S. and OsA, T. (1971) Membrane activity in guinea-pig gastric sling muscle: A nervedependent phenomenon. Am. J. Physiol., 220: 1397-1403.

Bülbring, E., Brading, A. F., Jones, A. W., and Tomita, T. (1970) Smooth muscle. Edward Arnold, London.

Chiaranbini, D. J. and Stefani, E. (1973) Effect of manganese on the electrical and mechanical properties of the frog skeletal muscle fibres. J. Physiol., 232: 129-147.

Dulhunty, A. and Gage, P. W. (1971) Selective effects of an octopus toxin on action potentials. J. Physiol., 218: 433-445.

FAtT, P. and Ginsborg, B. L. (1958) The ionic requirements for the production of action potentials in crustacean muscle fibres. J. Physiol., 142: 516-543.

Frankenhaeuser, B. and Hodgkin, A. L. (1957) The action of calcium on the electrical properties of squid axons. J. Physiol., 137: 218-244.

Hagiwara, S. and TAKAHASHI, K. (1967) Surface density of calcium ions and calcium spikes in the barnacle muscle fiber membrane. J. Gen. Physiol., 50: 583-601.

Horn, L., Kumamoto, M., and Niu, H. (1972) Effects of tetraethylammonium on the electrical activity of vascular smooth muscle. Jap. J. Smooth Muscle Res., 8: 253 (in Japanese).

Ito, Y., KuRIYAMA, H., and SAKAмото, Y. (1970) Effects of tetraethylammonium chloride on the membrane activity of guinea pig stomach smooth muscle. J. Physiol., 212: 445-460.

IwASAKI, S., SATOW, Y., and Kuroda, T. (1973) On the hyper-polarizing inactivation of the $\mathrm{Ca}^{++}$-dependent action potentials. Proc. Japan Acad., 49: 564-568.

Koketsu, K. and Mryamoto, S. (1961) The release of ${ }^{45} \mathrm{Ca}$ from frog nerves during electrical activity. Nature, 189: 402-403.

Koketsu, K. and NaKatake, K. (1973) Ca-current in the sympathetic ganglion of frogs. 50th Ann. Meet. Jap. Physiol. Soc. (in Japanese).

OsA, T. (1973a) The effects of sodium, calcium and manganese on the electrical and mechanical activities of the myometrial smooth muscle of pregnant mouse. Jap. J. Physiol., 23: 113-134.

OsA, T. (1973b) Some factors affecting the contractile responses of pregnant mouse myometrium. Jap. J. Physiol., 23: 401-417.

OsA, T. (1974) Modification of the mechanical response of the smooth muscles of pregnant mouse myometrium of pregnant mouse myometrium and guinea pig ileum by manganese and cadmium ions. Jap. J. Physiol., 24: 101-117.

OsA, T. and KuriYAmA, H. (1971) The membrane properties and decremental conduction of excitation in the fundus of the guinea pig stomach. Jap. J. Physiol., 20:626-639.

OsA, T. and TAGA, F. (1973) Effects of external $\mathrm{Na}$ and $\mathrm{Ca}$ on the mouse myometrium in relation to the effects of oxytocin and carbachol. Jap. J. Physiol., 23: 97-112.

Shanes, A. M. and Branchi, C. P. (1960) Radiocalcium release by stimulated and potassium treated sartorius muscles of the frog. J. Gen. Physiol., 43: 481-493.

Tomita, T. and WATANABE, H. (1973) On the spontaneous activity of the guinea pig taenia coli, 15th Ann. Meet. Jap. Smooth Muscle Res. (in Japanese).

Weidmann, S. (1955) Effects of calcium ions and local anaesthetics on electrical properties of Purkinje fibres. J. Physiol., 129: 568-582. 